\title{
Prevalência de anticorpos contra agentes virais e bacterianos em eqüídeos do Município de Monte Negro, Rondônia, Amazônia Ocidental Brasileira
}

\author{
Daniel Moura AGUIAR ${ }^{1}$ \\ Guacyara Tenório \\ CAVALCANTE ${ }^{2}$ \\ Maria do Carmo Custodio de \\ Souza Hunold LARA ${ }^{3}$ \\ Eliana Monteforte Cassaro \\ VILLALOBOS $^{3}$ \\ Elenice Maria Siquetin \\ CUNHA $^{3}$ \\ Liria Hiromi OKUDA ${ }^{3}$ \\ Eliana de STÉFANO ${ }^{3}$ \\ Alessandra Figueiredo de \\ Castro NASSAR ${ }^{3}$ \\ Gisele Oliveira SOUZA² \\ Silvio Arruda \\ VASCONCELLOS ${ }^{2}$ \\ Marcelo Bahia LABRUNA² \\ Luis Marcelo Aranha \\ CAMARGO $^{4}$ \\ Solange Maria GENNARI ${ }^{2}$ \\ Correspondência para: \\ Daniel Moura Aguiar - Agência Paulista de \\ Tecnologia dos Agronegócios \\ Rod. Raposo Tavares, Km 563, CP 298 \\ Presidente Prudente, SP, Brasil, \\ 19015-970.Tel. (18) 3222-8688, \\ danmoura@apta.sp.gov.br
}

Recebido para publicação: 28/09/2007 Aprovado para publicação: 24/04/2008

\author{
1 - Agência Paulista de Tecnologia dos Agronegócios, Presidente Prudente-SP \\ 2 - Faculdade de Medicina Veterinária e Zootecnia da Universidade de São Paulo, \\ São Paulo-SP \\ 3 - Instituto Biológico, São Paulo-SP \\ 4 - Instituto de Ciências Biomédicas da Universidade de São Paulo, São Paulo-SP
}

\section{Resumo}

Foram examinados 176 eqüídeos (15 muares e 161 eqüinos) do município de Monte Negro, Rondônia, Amazônia Ocidental Brasileira, frente a agentes virais e bacterianos. A amostra correspondeu ao total de eqüídeos no município, considerando um nível de confiança de $99 \%$, prevalência esperada de $50 \%$ e erro padrão de $10 \%$. As infecções virais foram investigadas pelas provas de Imunodifusão em gel de Agar (Anemia Infecciosa Eqüina - AIE), Inibição da hemaglutinação (Influenza eqüina tipos 1 e 2 - IE-1 e 2) e Soroneutralização em cultura celular (Arterite Viral Eqüina - AVE, Herpesvírus Eqüino tipo 1 - HVE1, Estomatite Vesicular - EV e Encefalomielite Eqüina do Leste - EEE, do Oeste - WEE e Venezuela - VEE). Para o diagnóstico da leptospirose, foi utilizada a prova de Soroaglutinação Microscópica (SAM); para o diagnóstico da brucelose, o teste do Antígeno Acidificado Tamponado (AAT) foi utilizado como teste de triagem e as provas de Soroaglutinação Lenta em Tubos (SLT) e 2mercaptoetanol como testes diagnósticos. Foram constatados 9,6\% dos eqüídeos reativos para AIE, 22,7\% para HVE1, 19,9\% para IE1, 42,0\% para IE-2, 21,0\% para EEE, 11,3\% para VEE, 3,4\% para Brucella spp. e 91,4\% para Leptospira spp. Os sorovares de leptospira mais freqüentes foram Bratislava (10,5\%), Icterohaemorrhagiae (8,7\%) e Autumnalis $(8,7 \%)$ nos eqüinos e Patoc $(26,6 \%)$ nos muares. Não foram encontrados animais com anticorpos contra AVE, EV e WEE.
Palavras-chave: Prevalência. Agentes virais. Agentes bacterianos. Eqüídeos. Monte Negro.

\section{Introdução}

A eqüideocultura brasileira é um importante segmento no agronegócio nacional, pois os cavalos e os muares são criados para os mais diversos propósitos, como tração, transporte, trabalho e esporte. Os eqüídeos são indispensáveis para a permanência e sobrevivência do homem no campo, principalmente na região norte, onde a atividade agropecuária tem sido intensificada nos últimos anos.

Devido as peculiaridades regionais, decorrente de aspectos ecológicos e sanitários, os poucos estudos epidemiológicos que avaliaram doenças infecciosas em eqǘdeos no Brasil apresentaram resultados divergentes, principalmente em relação as doenças virais como Anemia Infecciosa Eqüina (VAIE), Arterite Eqüina (VAE), Herpesvírus Eqüino tipo 1 (HVE 1) e Influenza eqüina (VIE). ${ }^{1,2,3,4}$ A Encefalomielite Eqüina (EE) foi investigada principalmente nas regiões Amazônica ${ }^{5}$ e Pantanal Mato-grossense ${ }^{4,6}$ enquanto que o vírus da Estomatite Vesicular (VEV) já foi detectado na região sul do Brasil ${ }^{7}$. As doenças causadas por agentes virais estão entre as mais importantes na espécie eqüina, pois determinam importantes prejuízos 
econômicos decorrentes de surtos epidêmicos e restrições no comércio de eqüinos. $^{8}$

A infecção de eqüídeos por agentes bacterianos como Brucella spp. e Leptospira spp. tem sido pouco estudada, principalmente na região norte do Brasil. $\mathrm{Na}$ espécie eqüina, os prejuízos econômicos advindos da infecção por Brucella spp são considerados de menor importância quando comparados a outras espécies de interesse zootécnico, entretanto a espécie merece atenção em virtude das lesões debilitantes, pela indicação de sacrifício, e por serem fontes de infecção para outras espécies domésticas e inclusive o homem. ${ }^{8,9}$ Eqüinos com anticorpos anti-Leptospira spp. foram observados em algumas regiões do Brasil, e sua presença é importante, pois podem atuar como portadores eliminando o agente na urina e possibilitando a contaminação ambiental e infecção do homem e de outras espécies de animais. ${ }^{10}$ Em contraste com a espécie eqüina, os dados referentes à ocorrência de infecções virais e bacterianas em muares são ainda mais escassos, particularmente no relativo a rebanhos brasileiros.

O presente estudo objetivou determinar a prevalência de anticorpos contra agentes virais (VAIE, VEV, VAE, HVE 1, VEE, VIE) e bacterianos (Brucella spp e Leptospira spp) em eqüinos e muares do município de Monte Negro, Estado de Rondônia, Amazônia Ocidental Brasileira.

\section{Material e Método}

O município de Monte Negro, RO, está localizado a oeste da Amazônia Brasileira (10 $18^{\prime} \mathrm{Sul} ; 6^{\circ} 14^{\prime}$ Oeste). A região é caracterizada por solos mistos e vegetação equatorial de terra firme e clima quente e úmido, com pluviosidade elevada (média anual variando entre $1.440 \mathrm{~mm}$ nos meses de novembro a abril e $557 \mathrm{~mm}$ no período seco, de maio a outubro), com temperaturas médias de 25 a $29^{\circ} \mathrm{C}$ e umidade relativa entre 70 a $80 \%$ durante o ano. ${ }^{11}$

Foram trabalhadas propriedades que participaram de um estudo delineado a analisar a leptospirose bovina ${ }^{11}$. A amostra foi planejada segundo a estimativa de prevalência esperada, tendo como unidade principal as propriedades rurais. Em 2002 havia em Monte Negro, 722 fazendas de criação de bovinos, as quais na sua maioria possuíam ao menos um eqüídeo (IDARON - Agência de Defesa Sanitária e Agrosilvopastoril do Estado de Rondônia). O número de fazendas a serem estudadas foi estipulado adotando-se o nível de confiança de 95\%, erro máximo de 10\% e prevalência estimada de $50 \%$. Foi amostrado sangue de todos os eqüídeos presentes nas propriedades no momento das visitas. $\mathrm{O}$ total de eqüídeos amostrados correspondeu ao número de eqüídeos no município no ano de 2002 que era de aproximadamente 1.900 animais $^{12}$, considerando um nível de confiança de $99 \%$, prevalência esperada de $50 \%$ e erro máximo de $10 \%$. As colheitas foram realizadas entre os meses de maio e outubro de 2002. Os cálculos para obtenção do número de animais foram realizados com o programa EpiInfo 6.04.

As amostras de sangue foram obtidas assepticamente por venopunção da jugular, com agulhas $21 \mathrm{G}$ apropriadas para tubos a vácuo. Os soros foram obtidos após a retração do coágulo e estocados a $-20^{\circ} \mathrm{C}$ até o momento dos exames laboratoriais.

A presença de anticorpos contra o VAIE foi efetuada por Imunodifusão em gel de ágar a $1 \%$ empregando-se antígeno comercial do Laboratório Bruch Ltda, segundo as normas recomendadas pelo fabricante.

Anticorpos contra VEV, VAE, HVE-1 e VEE [Encefalomielite Eqüina Leste (EEE), Oeste (WEE) e Venezuela (VEE)] foram pesquisados pela técnica de soroneutralização viral em cultivo de linhagem celular. A tabela 1 apresenta as amostras virais empregadas como antígeno para cada doença, bem como a linhagem celular, ponto de corte e referências utilizadas 13,14,15,16 para as análises em questão.

A pesquisa do VIE foi realizada pela técnica de inibição da hemaglutinação (HI). ${ }^{13}$ 
Tabela 1 - Amostra viral, linhagem celular e ponto de corte empregado para a pesquisa de anticorpos contra Estomatite Vesicular, Arterite Viral Eqüina, Herpesvírus eqüino tipo 1, Encefalomielite Eqüina Leste, Encefalomielite Eqüina Oeste e Encefalomielite Eqüina Venezuela, em eqüídeos do Município de Monte Negro, RO, segundo as referências adotadas para a realização dos exames sorológicos

\begin{tabular}{|c|c|c|c|c|}
\hline Doença & $\begin{array}{c}\text { Amostra viral empregada como } \\
\text { antigeno }\end{array}$ & Linhagem celular & $\begin{array}{c}\text { Ponto de corte } \\
\text { (Título-UI) }\end{array}$ & Referência \\
\hline Estomatite Vesicular & Indiana 1 Costa Rica $/ 72$ & VERO & $\geq 1,6$ & $\mathrm{OIE}^{13}$ \\
\hline Arterite Viral Eqüina & Bucyrus & RK-13 & $\geq 4,0$ & Senne et al. ${ }^{14}$ \\
\hline Herpesvinus eqüino tipo 1 & $\mathrm{~A} 4 / 72$ & VERO & $\geq 4,0$ & Kotait et al. ${ }^{15}$ \\
\hline Encefalomielite Eqüina Leste & Tatui & VERO & $\geq 10,0$ & Kotait et al. ${ }^{16}$ \\
\hline Encefalomielite Eqüina Oeste & $\operatorname{TR} 25717$ & VERO & $\geq 10,0$ & Kotait et al. ${ }^{16}$ \\
\hline Encefalomielite Eqüina Venezuela & SP AN 15600 & VERO & $\geq 10,0$ & Kotait et al. ${ }^{16}$ \\
\hline
\end{tabular}

Os soros foram testados frente aos antígenos tipo A Eq1 (amostra SP/56) e tipo A Eq2 (amostra SP/1/85) com quatro unidades hemaglutinantes (UHA) adicionando-se hemácia de galo 0,5\%. As amostras que apresentaram títulos de anticorpos iguais ou superiores a $20 \mathrm{UHI}$ foram consideradas positivas.

Para brucelose, as amostras foram examinadas pela prova do Antígeno Acidificado Tamponado (AAT) e foram confirmadas pela Soroaglutinação Lenta em Tubos (SAL) e pelo teste da Soroaglutinação Lenta em Tubos com 2-Mercaptoetanol (2$\mathrm{ME}) \cdot{ }^{17} \mathrm{O}$ critério adotado para o animal ser considerado como positivo foi o título maior ou igual a 25 no teste de 2-ME. Os antígenos utilizados nas provas de soroaglutinação foi a suspensão inativada de $B$. abortus estirpe 1119-3, produzida pelo Instituto de Tecnologia do Paraná (TECPAR).

A sorologia para Leptospira spp. foi realizada por meio da microtécnica de Soroaglutinação Microscópica (SAM) 18, 19 frente a uma coleção de 24 antígenos constituídos por sorovares de leptospiras vivas, cultivadas em meio líquido de EMJH modificado ${ }^{10}$ : Andamana, Australis, Autumnalis, Bataviae, Bratislava, Butembo, Canicola, Castellonis, Cinoptery, Copennhageni, Grippotyphosa, Hardjo, Hebdomadis, Icterohaemorrhagiae, Javanica, Panama, Pomona, Patoc, Pyrogenes, Sentot, Shermani, Tarassovi, Wolffi e Whitcombi. O sorovar considerado como mais provável foi o que apresentou maior título na SAM. Animais que apresentaram dois ou mais sorovares com títulos idênticos (coaglutinação) foram excluídos desta análise, sendo considerados apenas reatores para a Leptospira spp. O ponto de corte para a triagem foi um título maior ou igual $100 .^{10}$

As prevalências foram calculadas por propriedade e por animais, com intervalo de confiança de $95 \%$, com o programa estatístico EpiInfo 6.04.

\section{Resultados}

Foram obtidas amostras de sangue de 176 eqüídeos dos quais 161 eqüinos e 15 muares distribuídos em 67 propriedades, representando o total de eqüídeos presentes por ocasião das visitas. Os resultados das pesquisas de anticorpos frente aos diversos agentes estão sumarizados na tabela 2 .

Houve reações positivas para Leptospira spp. em 91,4\% (161/176) dos animais examinados. Todos os muares apresentaram anticorpos contra leptospira, sendo o sorovar Patoc, o mais freqüente (26,6\%). Dos eqüinos, 146 (90,7\%) animais foram reatores. Os sorovares predominantes foram Bratislava (10,5\%), Icterohaemorrhagiae $(8,7 \%)$ e Autumnalis (8,7\%). A tabela 3 apresenta os sorovares reatores para os muares e eqüinos por propriedades.

\section{Discussão}

$\mathrm{O}$ presente estudo pesquisou pela primeira vez a presença de anticorpos contra agentes virais e bacterianos em eqüídeos criados em propriedades do município de Monte Negro, RO, na Amazônia Ocidental Brasileira. 
Tabela 2 - Prevalência de anticorpos contra agentes virais e bacterianos em equídeos do município de Monte Negro, RO segundo as espécies estudadas (muar e equino), totais de animais e propriedades. Monte Negro, RO

\begin{tabular}{|c|c|c|c|c|c|c|c|c|}
\hline \multirow{3}{*}{ Agentes" } & \multicolumn{4}{|c|}{ Espécies } & \multicolumn{4}{|c|}{ Total } \\
\hline & \multicolumn{2}{|c|}{$\operatorname{Muar}(n=15)$} & \multicolumn{2}{|c|}{ Eqüina $(n=161)$} & \multicolumn{2}{|c|}{ Animais $(n=176)$} & \multicolumn{2}{|c|}{ Propriedades $(n=67)$} \\
\hline & Positivos & $\%$ (IC $95 \%)$ & Positivos & $\%$ (IC 95\%) & Positivos & $\%($ IC95\%) & Positivas & $\%$ (IC 95\%) \\
\hline VAIE & 02 & $13,3(2,0-37,5)$ & 15 & $9,3(5,5-14,5)$ & 17 & $9,6(5,9-14,7)$ & 16 & $23,8(14,8-35,1)$ \\
\hline VEV & 0 & $0(0-18,1)$ & 0 & $0(0-1,8)$ & 0 & $0(0-1,6)$ & 0 & $0(0-4,3)$ \\
\hline $\mathrm{VAE}$ & 0 & $0(0-18,1)$ & 0 & $0(0-1,8)$ & 0 & $0(0-1,6)$ & 0 & $0(0-4,3)$ \\
\hline HVE1 & 01 & $6,6(0,3-28,7)$ & 39 & $24,2(18,0-31,3)$ & 40 & $22,7(16,9-29,3)$ & 32 & $47,7(36,0-59,6)$ \\
\hline VIE-1 & 03 & $20,0(5,3,45,3)$ & 32 & $19,8(14,2-26,5)$ & 35 & $19,9(14,426,2)$ & 25 & $37,3(26,3-49,3)$ \\
\hline VIE-2 & 06 & $40,0(18,0-65,4)$ & $6 s$ & $42,2(34,7-50,0)$ & 74 & $42,0(34,9-49,3)$ & 44 & $65,7(53,7,76,2)$ \\
\hline EEE & 01 & $6,6(0,3-28,7)$ & 36 & $22,3(16,429,3)$ & 37 & $21,0(15,427,5)$ & 29 & $43,2(31,8-55,3)$ \\
\hline WEE & 0 & $0(0-18,1)$ & 0 & $0(0-1,8)$ & 0 & $0(0-1,6)$ & 0 & $0(0-4,3)$ \\
\hline VEE & 0 & $0(0-18,1)$ & 20 & $12,4(8,0-18,2)$ & 20 & $11,3(7,2-16,7)$ & 17 & $25,3(16,0-36,7)$ \\
\hline Brucella spp & 0 & $0(0-18,1)$ & $06^{*}$ & $3,7(1,5-7,5)$ & $06^{*}$ & $3,4(1,4-69)$ & 02 & $2,9(0,5-9,5)$ \\
\hline Lepiospira spp & 15 & $100,0(\$ 1,9-100)$ & 146 & $90,7(85,4,94,5)$ & 161 & $91,4(86,6-95,0)$ & 55 & $82,0(71,5-89,9)$ \\
\hline
\end{tabular}

VEV vírus da Estomatite Vesicular; VAE vírus da Arterite Eqüina; HVE1 Herpesvírus eqüino tipo 1; VIE 1 e 2 vírus da Influenza eqüina tipos $1 \mathrm{e} 2$;

EEE vírus da Encefalomielite Eqüina Leste; WEE vírus da Encefalomielite Equina Oeste; VEE vírus da Encefalomielite Eqüina Venezuela.

Dezesseis das sessenta e sete $(23,8 \%)$

propriedades estudadas apresentaram animais reagentes ao VAIE, totalizando 17 (9,6\%) eqüídeos soropositivos. Resultado semelhante foi relatado por Santos et al. ${ }^{20}$ no estado Acre com 14,5\% de propriedades positivas e $7,5 \%$ de animais reagentes. No entanto, os valores de prevalência do presente estudo estão abaixo dos obtidos por Heinemann et al. ${ }^{3}$ no Estado do Pará $(17 \%)$, e por Silva et al. ${ }^{4}$ no Pantanal Matogrossense $(24,8 \%)$. A região amazônica apresenta características regionais que propiciam a manutenção de vetores hematófagos, responsáveis pela transmissão desta doença. Os resultados do presente estudo, mesmo que inferiores aos observados em outras regiões do Brasil, demonstram que a infecção está disseminada na região Amazônica.

Não foram detectados anticorpos contra o VEV. A estomatite vesicular tem apresentado incidência sazonal, ocorrendo principalmente após as chuvas em regiões de clima tropical, o que sugere que a transmissão do vírus possa ser veiculada por insetos hematófagos. ${ }^{21}$ Kotait $^{22}$ ao estudar a ocorrência em eqüinos e bovinos do Vale do Paraíba, SP observou que a mesma ocorreu em seguida a um período de chuvas, reforçando a teoria de transmissão por insetos hematófagos. Como as amostras de sangue no presente estudo foram colhidas durante o período seco (de maio a outubro de 2002), provavelmente houve influência sazonal no resultado da pesquisa de anticorpos.

Não foram observados animais reagentes a pesquisa de anticorpos contra o VAE. Inquéritos soroepidemiológicos no Brasil têm demonstrado freqüências variando de 2,2\% no Rio Grande do Sul ${ }^{1}$ a 18,2\% no Estado de São Paulo ${ }^{23}$. Heinemann et al. ${ }^{3}$, também no Estado do Pará, não observaram animais soropositivos, sendo provável que a baixa atividade viral observada na região norte seja decorrente da menor aglomeração animal, e caso a infecção ocorra no município estudado, à prevalência deverá ser menor ou igual a $1,6 \%$.

Foi observado que 47,7\% (32/67) das propriedades possuíam eqüídeos $(22,7 \%$; 40/176) soropositivos para HVE1. Segundo informações dos proprietários nenhum animal foi vacinado contra o agente, portanto todas as reações são indicativas de infecção natural. Os valores encontrados estão bem 
Tabela 3 - Número e freqüencia de equídeos (muares e equinos) e propriedades positivas à pesquisa de anticorpos anti-Leptospira spp pela Soroaglutinação Microscópica (SAM)

\begin{tabular}{|c|c|c|c|c|c|c|}
\hline \multirow[t]{2}{*}{ Sorovares } & \multicolumn{2}{|c|}{$\begin{array}{l}\text { Muares } \\
(n=15)\end{array}$} & \multicolumn{2}{|c|}{$\begin{array}{l}\text { Eqüinos } \\
(n=161)\end{array}$} & \multicolumn{2}{|c|}{$\begin{array}{c}\text { Propriedade } \\
(n=67) \\
\end{array}$} \\
\hline & Reagentes & $\%$ & Reagentes & $\%$ & Reagentes & $\%$ \\
\hline Bratislava & 0 & 0 & 17 & 10,5 & 11 & 16,4 \\
\hline Icterohaemorrhagiae & 0 & 0 & 14 & 8,7 & 12 & 18,0 \\
\hline Autumnalis & 0 & 0 & 14 & 8,7 & 12 & 18,0 \\
\hline Pyrogenes & 0 & 0 & 13 & 8,0 & 10 & 15,0 \\
\hline Hardjo & 0 & 0 & 06 & 3,7 & 05 & 7,5 \\
\hline Patoc & 04 & 26,6 & 05 & 3,1 & 07 & 10,5 \\
\hline Grippotyphosa & 0 & 0 & 04 & 2,5 & 04 & 6,0 \\
\hline Shermani & 0 & 0 & 03 & 1,8 & 03 & 4,5 \\
\hline Butembo & 01 & 6,6 & 03 & 1,8 & 03 & 4,5 \\
\hline Hebdomadis & 01 & 6,6 & 0 & 0 & 1 & 1,5 \\
\hline Canicola & 0 & 0 & 01 & 0,62 & 1 & 1,5 \\
\hline Andamana & 0 & 0 & 01 & 0,62 & 1 & 1,5 \\
\hline Copenhageni & 0 & 0 & 01 & 0,62 & 1 & 1,5 \\
\hline Pomona & 0 & 0 & 01 & 0,62 & 1 & 1,5 \\
\hline Wolffi & 0 & 0 & 01 & 0,62 & 1 & 1,5 \\
\hline Inconclusivo & 9 & 60,0 & 62 & 38,5 & 48 & 71,6 \\
\hline
\end{tabular}

próximos aos relatados por Heinemann et al. $^{3}$ de $40 \%$ para propriedades e $17 \%$ para os animais no município de Uruará, PA. Outros estudos no Brasil já registraram anticorpos contra Herpesvírus eqüino. Diel et al. ${ }^{1}$ no Estado do Rio Grande do Sul e Cunha et al. $^{2}$ em São Paulo registraram percentuais respectivos de 2,2\% e $27,2 \%$ de animais reagentes, o que corrobora a afirmação de que a infecção por Herpesvírus em eqüinos está disseminada em todo o país.

Foram encontrados anticorpos para os dois sorotipos virais de Influenza Eqüina (Influenza A/ equine 1 e Influenza A/ equine 2 ), entretanto as maiores freqüências foram observadas para o subtipo 2. Nas duas espécies estudadas, a prevalência foi de $42,0 \%$ (74/176; 65\% das propriedades). No Brasil o subtipo 2 já foi detectado nos estados do Rio Grande do Sul ${ }^{1}$, Mato Grosso ${ }^{4}$, Rio de Janeiro ${ }^{24}$ e Pará ${ }^{25}$ com freqüências de ocorrência variando de $30 \%$ a $65 \%$, portanto próximas às encontradas no presente estudo.
Dados referentes à presença do subtipo 1 são escassos na literatura, e no Brasil ainda não havia sido registrado sua ocorrência.

Não foram detectados animais reagentes para a WEE, concordando com os achados de Silva et al. ${ }^{4}$, Iversson et al. ${ }^{6}$ e Heinemann et al. ${ }^{26}$ que relataram freqüências próximas a 1,2\% nas regiões do Pantanal Mato-grossense e do sul do Estado do Pará. Para o VEE houve 12,4\% (20/161) de positividade para os eqüinos. A ocorrência deste vírus ainda é pouco conhecida, destacando-se o registro de anticorpos em eqüinos com sintomas neurológicos na região do Pantanal Mato-grossense. ${ }^{4,6}$ Neste estudo não foram observados animais com sintomatologia neurológica e a presença de anticorpos evidencia apenas uma infecção passada. Dentre os vírus da encefalomielite estudados, EEE foi o que apresentou maiores valores de soroprevalência (21\%; $37 / 176)$, sendo estes semelhantes aos encontrados no Pará ${ }^{26}$ e superiores aos 
valores observados no pantanal ${ }^{4,6}$. As regiões da Amazônia e do pantanal oferecem condições ecológicas propicias para a manutenção destes vírus, pois apresentam ampla variedade de aves (reservatórios naturais) nativas e migratórias, e um grande contingente de insetos vetores. ${ }^{5}$

Apenas seis eqüinos $(3,7 \%)$ de duas propriedades $(2,9 \%)$ apresentaram anticorpos anti-Brucella spp. Ribeiro et al. ${ }^{9}$ consideram que a infecção na espécie eqüina seja favorecida pela coabitação com outras espécies domésticas infectadas. Aguiar et al. ${ }^{27}$, investigando a brucelose bovina nas mesmas propriedades deste estudo, detectaram a infecção em $63 \%$ das fazendas, corroborando as afirmações de Ribeiro et al. .

Oitenta de dois por cento das propriedades apresentaram no mínimo um eqüídeo infectado por Leptospira spp., com a prevalência nos animais de 91,4\% (161/ 176), com $100 \%$ dos muares e $90,7 \%$ dos eqüinos reagindo frente a pelo menos um sorovar da coleção empregada. Para os muares, o sorovar Patoc foi o mais prevalente $(26,6 \%)$, sendo este um sorovar da Leptospira biflexa, saprófita e de vida livre. Este sorovar é utilizado como indicador sorológico, pois costuma reagir precocemente, além do que, há relatos de reações cruzadas com sorovares patogênicos, fazendo com que seja freqüentemente utilizado nas coleções de antígenos. ${ }^{11}$

Nos eqüinos o sorovar mais freqüente foi Bratislava $(10,5 \%)$ seguido de Icterohaemorrhagiae e Autumnalis, ambos com $8,7 \%$ das reações positivas. O sorovar Bratislava tem sido apontado como adaptado à espécie eqüina, em virtude da alta freqüência detectada em inquéritos sorológicos e da ausência de sintomatologia clínica ${ }^{8}$ Por outro lado, este sorovar também tem sido associado à infecção em suínos, de fato nestas propriedades, os suínos já foram classificados como reatores para o sorovar Bratislava. ${ }^{28}$ Segundo Fávero et al. ${ }^{10}$, a presença do sorovar Icterohaemorrhagiae sugere a participação de roedores sinantrópicos. O sorovar Autumnalis também foi detectado nas propriedades estudadas, em bovinos, suínos, cães e humanos ${ }^{11}, 28,29,30$, entretanto ainda são poucas as informações epidemiológicas a respeito desse sorovar em outras regiões do país.

Os resultados apontam para a ocorrência de atividade viral em eqüídeos da Amazônia Ocidental Brasileira e a circulação desses agentes alerta para a necessidade de estratégias de controle na região. Leptospira spp. encontra-se presente na região, acometendo diversas espécies animais, sobretudo os eqüídeos, por sorovares mantidos por animais domésticos e silvestres. Deve-se ainda ressaltar a ocorrência de equídeos positivos para brucelose, ressaltando a promiscuidade existente na criação das diferentes espécies animais.

\section{Agradecimentos}

À Fundação de Amparo a Pesquisa do Estado de São Paulo pelo auxílio concedido a esta pesquisa e concessão de Bolsa de doutorado de G.T. Cavalcante. Ao Conselho Nacional de Desenvolvimento Científico e Tecnológico (CNPq) pela bolsa de produtividade em pesquisa concedida à M.B. Labruna, S.A. Vasconcellos e S.M. Gennari.

\section{Seroprevalence of viral and bacterial agents in equids from Monte Negro Municipality, State of Rondônia. Brazilian Western Amazon}

\section{Abstract}

Sera from 174 equidaes (15 mules and 161 equines) of Monte Negro municipality, Rondônia State were analyzed against viral and bacterial agents. The serum sample corresponded the total equid population
Key words: Prevalence. Viral agents. Bacterial agents. Equids. Monte Negro. 
in the municipality considering a confidence interval of $99 \%$, expected prevalence of $50 \%$ and absolute desired of $10 \%$. For the viral agents, sera were tested by the Agar Gel Immunodiffusion Test (Equine Infection Anemia - EIA), Inhibition Haemagglutination Test (Equine Influenza 1 and 2 - EI-1 and 2), and Virusneutralizating Tests (Equine Viral Arteritis - EVA, Equine Herpesvirus 1 - EHV1, Vesicular Stomatitis - VS, Equine Encephalitis Eastern - EEE, Western - WEE and Venezuelan VEE). The diagnosis for brucellosis was made by Agglutination Tests and the Microscopic Agglutination Test was used for leptospirosis. The results showed positivity of 9.6\% for EIA, $22.7 \%$ for HVE1, $19.9 \%$ for IE-1, $42.0 \%$ for IE-2, $21.0 \%$ for EEE, $11.3 \%$ for VEE, 3.4\% for brucellosis, and $91.4 \%$ for leptospirosis. The most frequent serovars detected were Bratislava $(10.5 \%)$, Icterohaemorrhagiae $(8.7 \%)$, Autumnalis $(8.7 \%)$ for equines and Patoc $(26.6 \%)$ for mules. No one of the examined samples reacted to EVA, VS, or WEE.

\section{Referências}

1 DIEL, D. et al. Prevalence of antibodies to influenza virus, viral arteritis and herpesvirus in horses of the Rio Grande do Sul state, Brazil. Ciência Rural, v. 36, n. 5, p. 1467-1473, 2006.

2 CUNHA, E. M. S. et al. Presença de anticorpos contra o herpesvírus eqüino 1 (HVE-1) em eqüinos do noroeste do Estado de São Paulo. Arquivos do Instituto Biológico, v. 69, n. 1, p. 1-5, 2002.

3 HEINEMANN, M. B. et al. Soroprevalência da anemia infecciosa eqüina, da arterite viral dos eqüinos e do aborto viral eqüino no município de Uruará, PA, Brasil. Brazilian Journal of Veterinary Research and Animal Science, v. 39, n. 1, p. 50-53, 2002.

4 SILVA, R. A. M. S. et al. Equine viral diseases in the Pantanal, Brazil. Studies carried out from 1990 to 1995. Revue d'Élevage et de Médecine Vétérinaire des Pays Tropicaux, v. 52, n. 1, p. 9-12, 1999.

5 VASCONCELOS, P. F. C. et al. Epidemiologia das encefalites por arbovírus na Amazônia brasileira. Revista do Instituto de Medicina Tropical de São Paulo, v. 33, n. 6, p. 465-476, 1991.

6 IVERSSON, L. B. et al. Circulation of Eastern equine encephalitis, Western equine encephalitis, Ilhéus, Maguari and Tacaiuma viruses in equines of the Brazilian Pantanal, South America. Revista do Instituto de Medicina Tropical de São Paulo, v. 35, n. 4, p. 355359, 1993.

7 STEFANO, E. et al. Pesquisa de anticorpos contra o vírus da Estomatite Vesicular em bovinos de corte criados na região de Araçatuba, Estado de São Paulo, Brasil em 2000. Brazilian Journal of Veterinary Research and Animal Science, v. 40, n. 1, p. 29-35, 2003.

8 RADOSTITS, O. M. et al. Veterinary medicine. 9. ed. London: W.B.Saunders, 2000. p. 1877.
9 RIBEIRO, M. G. et al. Anti-Brucella abortus agglutinins in serum and secretion of fistulous withers in horses. Arquivo Brasileiro de Medicina Veterinária e Zootecnia, v. 55, n. 1, p. 99-101, 2003.

10 FAVERO, A. C. M. et al. Sorovares de leptospiras predominantes em exames sorológicos de bubalinos, ovinos, caprinos, eqüinos, suínos e cães de diversos estados brasileiros. Ciência Rural, v. 32, n. 4, p. 613619, 2002.

11 AGUIAR, D. M. et al. Seroprevalence of Leptospira spp in cattle from Monte Negro Municipality, Western Amazon, Brazil. Pesquisa Veterinária Brasileira, v. 26, n. 2, p. 102-104, 2006.

12 IBGE. Instituto Brasileiro de Geografia e Estatística. 2007. Disponível em: <http://www.ibge.gov.br/ cidadesat/default.php > . Acesso em: jan. 2007.

13 OFFICE INTERNATIONAL DES EPIZOOTIES. Manual of diagnostic tests and vaccines for terrestrial animals. 2006 Disponível em: < http://www.oie.int/ eng/nomes/mmanual/A_00083 $>$. Acesso em: jun. 2006.

14 SENNE, D. A.; PEARSON, J. E.; CARBREY, E. A. Equine viral arteritis: a standard procedure for the virus neutralization test and comparison of results of a proficiency test performed at five laboratories. Proceedings of United State Animal Health Association, v. 89, p. 29-34, 1985.

15 KOTAIT, I. et al. Diagnóstico laboratorial do aborto eqüino a vírus através de imunofluorescência e soroneutralização. Revista de Microbiologia, v. 20, n. 1, p. 128-132, 1989.

16 KOTAIT, I. Isolamento e identificação do vírus da encefalomielite eqüina, tipo leste, em eqüinos do Estado de São Paulo, Brasil. Arquivos do Instituto Biológico, v. 59, n. 1/2, p. 37-41, 1992.

17 ALTON, G. G.; JONES, L. M.; PIETZ, D. E. Las técnicas de laboratorios en la brucellosis. 2. ed. Genebra: FAO/WHO, 1976. 173 p. 
18 COLE JUNIOR, J. R.; SULZER, C. R.; PURSELL, A. R. Improved Microtechnique for the Leptospiral Microscopic Agglutination Test. Applied Microbiology, v. 25, p. 970-980, 1973.

19 GALTON, M. M. et al. Application of a Microtechnique to the Agglutination Test for Leptospiral Antibodies. Applied Microbiology, v. 13, p. 81-85, 1965.

20 SANTOS, R. M. L. et al. Freqüência de anemia infecciosa em eqüinos no Acre, 1986 a 1996. Arquivo Brasileiro de Medicina Veterinária e Zootecnia, v. 53, n. 3, p. 310-315, 2001

21 ACHA, P. N.; SZYFRES, B. Zoonosis y enfermedades transmisibles comunes al hombre y a los animales: Chlamydioses, Rickettsioses and Viroses. 3. ed. Washington: OPAS, 2001. 480 p.

22 KOTAIT, I. Estudo epidemiológico da estomatite vesicular no vale do Paraíba, São Paulo. 1990. 85 p. Dissertação (Mestrado em Epidemiologia) - Faculdade de Saúde Pública, Universidade de São Paulo, São Paulo, 1990.

23 LARA, M. C. C. S. H. et al. Prevalência de anticorpos antivírus da arterite dos eqüinos em cavalos criados no Estado de São Paulo. Arquivo Brasileiro de Medicina Veterinária e Zootecnia, v. 54, n. 3, p. 223-227, 2002.

24 OLIVEIRA, G. S. et al. Prevalência de anticorpos para o vírus da Influenza Eqüina, subtipo H3N8, em eqüídeos apreendidos no Estado do Rio de Janeiro.
Ciência Rural, v. 5, n. 5, p. 1213-1215, 2005.

25 PENA, L. J. et al. Levantamento soro-epidemiológico da infecção pelo vírus da Anemia Infecciosa Eqüina, da Influenza Eqüina-2 e do Herpesvírus Eqüino-1 em rebanhos do sul do estado do Pará, Brasil. Brazilian Journal of Veterinary Research and Animal Science, $v$. 43, n. 4, p. 537-542, 2006.

26 HEINEMANN, M. B. et al. Soroprevalência da encefalomielite eqüina do leste e oeste no Município de Uruará, PA, Brasil. Brazilian Journal of Veterinary Research and Animal Science, v. 43, p. 137-139, 2006.

27 AGUIAR, D. M. et al. Risk factors and seroprevalence of Brucella spp. in cattle from Western Amazon, Brazil. Arquivos do Instituto Biológico, v. 74, n. 4, p. 301-306, 2007.

28 AGUIAR, D. M. et al. Anticorpo contra agentes bacterianos e virais em suínos de agricultura familiar do Município de Monte Negro, RO. Arquivos do Instituto Biológico, v. 73, n. 4, p. 415-419, 2006.

29 AGUIAR, D. M. et al. Fatores de risco associados à ocorrência de anticorpos anti-Leptospira spp. em cães do município de Monte Negro, Rondônia, Amazônia Ocidental Brasileira. Arquivo Brasileiro de Medicina Veterinária e Zootecnia, v. 59, n. 1, p. 70-76, 2007.

30 AGUIAR, D. M. et al. Anti-Leptospira spp and antiBrucella spp antibodies in humans from rural area of Monte Negro municipality, state of Rondônia Brazilian western Amazon. Brazilian Journal of Microbiology, v. 38, n. 1, p. 93-96, 2007. 